\title{
OS MÉTODOS ALTERNATIVOS DE SOLUÇÃO DE CONFLITOS: MEDIAÇÃO E CONCILIAÇÃO
}

\author{
Olivie Samuel Paião \\ Universidade do Oeste Paulista - UNOESTE, curso de Direito, Presidente Prudente, SP. \\ E-mail: olivie-samuel@hotmail.com
}

\section{RESUMO}

O presente artigo tem como objetivo apresentar uma reflexão sobre a importância dos métodos alternativos de solução de conflito na sociedade contemporânea, propondo a adoção das técnicas conciliatórias para propiciar um desafogo do poder judiciário. Abordar-se-ão os conceitos e quando se aplica cada técnica conciliatória, tendo por objetivo demonstrar a viabilidade de tais métodos alternativos, visando minimizar o aumento das demandas do judiciário, bem como atender aos princípios processuais civis. A metodologia constou de pesquisas bibliográficas. Os dados obtidos foram analisados utilizando-se do método hipotético dedutivo. Conclui-se que os métodos de solução de conflito são as técnicas autocompositivas, que demonstram uma alternativa tanto aos conflitantes quanto ao judiciário de solver consensual e celeremente os litígios, atendendo aos princípios processuais e evitando sobrepeso de processos aos magistrados.

Palavras-Chave: Conciliação, Mediação, Judiciário, Processo Civil, Autocomposição.

\section{THE ALTERNATIVE METHODS OF CONFLICT SOLUTION: MEDIATION AND CONCILIATION}

\begin{abstract}
This article aims to present a reflection on the importance of alternative methods of conflict resolution in contemporary society, proposing the adoption of conciliatory techniques to provide a solution to the problem of the judiciary. Concepts will be discussed and when each conciliatory technique is applied with the objective of demonstrating the viability of such alternative methods, in order to minimize the increase of the demands of the judiciary, as well as to comply with the civil procedural principles. The methodology consisted of bibliographic research the data were analyzed using the hypothetical deductive method. It is concluded that the conflict resolution methods are the self-composed techniques that demonstrate an alternative to both the conflicting and the judiciary solver consensual and swiftly litigation in accordance with procedural principles and avoiding overweight cases to magistrates.
\end{abstract}

Keywords: Conciliation, Mediation, Judiciary, Civil Procedure, Self Composition.

\section{INTRODUÇÃO}

Há tempos atrás, os conflitos se resolviam pela lei do mais forte, a denominada autotutela. Naquele período não se falava em terceiro imparcial capacitado para resolver os problemas sociais de forma isonômica e justa. De tal forma, quem vencia as batalhas travadas com alguém era o certo, enquanto ao perdedor não sobrava razão. Visualizando que esta forma de composição não era a melhor forma de resolução, apareceu a necessidade de uma terceira pessoa resolver os conflitos que assolavam a sociedade. Este novo modelo de solver os conflitos denominou-se heterocomposição (ORDEM DOS ADVOGADOS DO BRASIL, 2015).

Com o passar dos anos, os terceiros, atualmente os juízes, que resolviam as lides, começaram a ter acúmulo de tarefas, haja vista que todos os problemas, independente do nível de 
dificuldade de solução, Ihes eram depositados, com o encargo de solucioná-los rápida e efetivamente.

Surge, então, a necessidade de um meio alternativo de solução de conflitos para evitar que demandas de soluções mais simplificadas adentrem o judiciário, corroborando com a agilidade da solução das lides. Assim, apresentam-se os meios autocompositivos, a mediação e a conciliação, como métodos alternativos.

Ganham importância os meios extrajudiciais autocompositivos notadamente a conciliação e a mediação -, reputados como mais acessíveis, ágeis, informais, econômicos e procedimentalmente mais orientados à pacificação. Seus facilitadores teriam também maior disponibilidade e proximidade para compreensão das realidades das partes, com desafogo da estrutura judiciária. (ORDEM DOS ADVOGADOS DO BRASIL, 2016, p.166).

Ante a importância da implantação dos meios de solução extrajudiciais supracitados, estes foram incluídos no Novo Código de Processo Civil, demonstrando que a postulação judicial não é o único meio de resolução de conflitos e que os problemas podem ser resolvidos antes mesmo da interposição de uma demanda sob a égide do Poder Judiciário.

\section{METODOLOGIA}

O artigo respaldou-se em pesquisas bibliográficas, das quais resultaram a leitura e análise de leis, resoluções e artigos eletrônicos. As informações foram analisadas e confrontadas com uso da dialética e a análise dos dados foi realizada com a aplicação do método hipotético-dedutivo, isto é, partindo do geral para o particular.

\section{DISCUSSÃO}

Um dos princípios jurídicos é a pacificação social, com respaldo de uma justiça equitativa e justa para com todos. Isto é, em outras palavras, vem para auxiliar as pessoas em todas as esferas, pautando-se na cooperação, harmonização e composição de conflitos que existirem. Nos dizeres de Braga (2004, p.21):

A proteção do direito é indispensável para que se garanta a convivência humana. Por isso, o Estado, por meio de um longo processo histórico, foi tomando para si a função de "restabelecer a ordem jurídica quando violada, ou mesmo de preservá-la, se apenas ameaçada de violação, ou simplesmente de integrá-la".

Primitivamente, antes da existência de um Estado que se impõe para compor conflitos e de leis regulamentadoras, existia a autotutela - um sistema onde quem tinha razão era o mais forte. Tal sistema não possuía nenhum tipo de justiça, desta forma, para garantir ou constituir um direito, o único meio era o uso da violência e da força (CINTRA; GRINOVER; DINAMARCO, 2008).

Diante dos entraves observados nesse contexto, pela aplicação da autotutela, viu-se a necessidade de terceiro imparcial resolver as lides, passando-se primeiro este poder a sacerdotes e anciões. Algum tempo depois, o Estado, percebendo que o poder de resolver todas as lides era grande, decide que, aqueles a quem caberia resolver as mesmas deveriam ser indivíduos qualificados com a imparcialidade, a ética e o conhecimento. Surgiam aí os Juízes e a Jurisdição.

Em síntese (CINTRA; GRINOVER; DINAMARCO, 2008, p. 28):

Na autotutela, aquele que impõe ao adversário uma solução não cogita de apresentar ou pedir a declaração de existência ou inexistência do direito 
satisfaz simplesmente pela força (ou seja, realiza sua pretensão). A autocomposição e a arbitragem, ao contrário, limitam-se a fixar a existência ou inexistência do direito: o cumprimento da decisão, naqueles tempos iniciais, continuava dependendo da imposição de solução violenta e parcial (autotutela).

O judiciário, como meio de acesso à justiça, foi atingido com grande proporção de demandas. A evolução da sociedade, os inúmeros eventos sociais, aumento populacional e o advento da globalização, tornaram constantes os conflitos, o que fez com que mais processos e desacordos surgissem e aumentassem exponencialmente. Assim, houve significativo crescimento no número de demandas no judiciário e, visando garantir a celeridade e economia processuais, surgiram os métodos alternativos de solução de conflitos.

Nos tempos mais remotos, não se falava em conciliação e mediação como atualmente. Conforme disposto pelo mestre Ricardo Ranzolin, no CPC anotado da Ordem dos Advogados do Brasil (2015, p.166):

Ganham importância os meios extrajudiciais autocompositivos notadamente a conciliação e a mediação -, reputados como mais acessíveis, ágeis, informais, econômicos e procedimentalmente mais orientados à pacificação. Seus facilitadores teriam também maior disponibilidade e proximidade para compreensão das realidades das partes, com desafogo da estrutura judiciária.

Transcorridos anos, constaram que o melhor caminho para resolução de conflitos nem sempre era a via processual contenciosa, logo, um novo modelo foi proposto, aquele em que as partes renunciariam parte de seus interesses a fim de se obter uma convergência e de solucionar o problema. Surge, então, a autocomposição, que é o instituto aplicado somente às causas admitidas nos juizados especiais e outras providências, lei 9.099/95, e, recentemente, com a entrada em vigência da lei 13.105/15, nas audiências de conciliação e/ou mediação.

O Novo código de processo civil, instituído pela lei 13.105 de 16 de Março de 2015, que entrou em vigor no dia 18 de março de 2016, tem uma visão completamente diferente no âmbito de solução de conflitos do código anterior (de 1973). Os primeiros artigos e parágrafos que fazem a abertura do novo código, especificamente art. 3ํ e seus $\S \S s ~ 20$ e 3으, já apontam uma nova visão de acesso à justiça adotando uma nova concepção. Neste sentido, à esteira das concepções preconizadas primordialmente por Cappelletti (1994), a ação judicial passa a ser forma residual para o estabelecimento da paz social.

A técnica de autocomposição, que foi incluída, em termos, obrigatoriamente, no Novo Código de Processo Civil tem marco significativo na mudança do Código anterior. Na figura da autocomposição positivou-se a mediação e conciliação estimuladas pelo Conselho Nacional de Justiça (CNJ); e a arbitragem, que possui lei própria (lei 9.307/1996). Ressalta-se que, mediante a nova política judiciária, benefícios serão gerados, tais como celeridade e economia processuais, haja vista que a conciliação e mediação podem ser, inclusive, pré-processuais, quando realizados em centros judiciários de solução conflitos. Estas audiências são conduzidas pela pessoa do mediador ou conciliador, conforme disposto no novo Código de Processo Civil (DIDIER, 2015).

Observando etimologicamente, conciliar significa apaziguar, possibilitar que litigantes cheguem a um consenso, ou seja, se reconciliem.

O Paradigma do novo código é que todas as ações judiciais deverão, antes de adentrar a via contenciosa, passar por uma audiência de conciliação e mediação, a fim de encontrar uma resolução para conflito de interesses de modo mais rápido e fácil, o que economizará atos 
processuais e atenderá aos interesses das partes. Assim, Teresa Arruda Alvim Wambier defende que (et al, 2015, p. 310):

[...] Ao incluir a conciliação e mediação no sistema processual do NCPC, o legislador inovou positivamente nesse assunto. Nos últimos anos, a busca de meios adequados de solução de conflitos e o incentivo às técnicas de autocomposição, tornaram-se cada vez mais frequentes. O que demonstra que a disciplina das atividades dos conciliadores e mediadores, prevista no NCPC, fortalecerá, ainda mais, a prática que já vem sendo adotada no sistema atual.

No Código de Processo Civil de 73, não havia a previsão da audiência conciliatória. O que se tinha era uma Resolução do CNJ, no 125/2010, prevendo a instalação de núcleos ou centrais de conciliação.

A chegada da conciliação desmistifica a ideia de que a única maneira de resolução de conflitos é por via contenciosa, ou seja, por meio de um processo, cujo tempo pode ser ou não demorado, sendo oneroso, havendo produção de provas, tendo que passar por várias fases, etapas, procedimentos e estar suscetível a várias possibilidades de dilação de prazo, bem como suspensões, ou técnicas para retardar o processo. Por fim, culminará em uma decisão vertical, vinda de um terceiro imparcial, denominado juiz, com imposição deste terceiro, para que se cumpra àquilo a que foi decidir (TOURINHO, 2007). Esta ideia foi desfragmentada, pois, com a nova técnica, não há imposição de decisões, mas, sim, um terceiro que tem uma postura ativa, com o intuito de ser facilitador da resolução para as partes, e neutro. É um processo consensual breve, ou seja, as partes, por livre e espontânea vontade, resolvem aquilo que as fazem litigar em menor tempo, custo e desgaste físico. O conciliador/mediador tenta estabelecer uma efetiva harmonização e restauração da relação social entre as partes.

Essa composição tenta retirar a ideia de briga judicial, tanto que as centrais de conciliação seguem normas relativas a quem os presidirá, como serão as posições e formas dos móveis e os locais em que devem ser as centrais - por exclusão, fora dos fóruns judiciais - e como devem proceder e argumentar os conciliadores e mediadores.

Faz-se necessário, assim, explanar, um pouco mais, a respeito dos institutos da Mediação e Conciliação.

A mediação é um meio de composição em que um agente facilita a conversação das partes, amenizando os ânimos para que as próprias partes, por meio de conversa, se resolvam e cheguem a um acordo comum, visando que ambas saiam satisfeitas da sala de mediação [...] num acordo criativo em que as duas partes aufiram ganhos. Sua utilização tem proliferado em relação aos conflitos no campo de atuação do Direito de Família. Logo, a principal característica da mediação é a de propiciar oportunidades para a tomada de decisões pelas partes conflitantes (SELTON, 2014).

A mediação é conduzida por um terceiro denominado mediador e, de acordo com o art. $165, \S 3$ ㅇ:

Art. $165[\ldots]$ :

§3ㅇ O mediador, que atuará preferencialmente nos casos em que houver vínculo anterior entre as partes, auxiliará aos interessados a compreender as questões e os interesses em conflito, de modo que eles possam, pelo restabelecimento da comunicação, identificar, por si próprios, soluções consensuais que gerem benefícios mútuos. (BRASIL, 2015)

Entende-se, portanto, o já afirmado, ou seja, que na mediação as partes chegam a um 
consenso. Segundo Maria Helena Diniz (apud TOURINHO; JUNIOR, 2007, p. 80) "é o negócio bilateral pelo qual as partes interessadas, fazendo-se concessões mútuas, previnem ou extinguem obrigações litigiosas ou duvidosas".

A conciliação pode ser visualizada tanto no meio judicial quanto no extrajudicial e é capaz de harmonizar conflitos, sendo possibilitado ao conciliador, caso as partes não cheguem a um consenso, apresentar uma solução - podendo ou não ser acatada pelas partes.

Pelo art. 165, §2ㅇq quanto à atuação do conciliador, dispõe:

Art. $165[\ldots]$ :

$\S 2$ 20 conciliador, que atuará preferencialmente nos casos em que não houver vínculo anterior entre as partes, poderá sugerir soluções para o litígio, sendo vedada a utilização de qualquer tipo de constrangimento ou intimidação para que as partes conciliem. (BRASIL, 2015).

E, com base neste parágrafo do Código de Processo Civil, entende-se que a conciliação é mais indicada aos conflitos que não envolvem relacionamentos anteriores que precisam ou pretendem ser continuados (casos de conflitos familiares ou sócios de sociedade empresarial, por exemplo), pois, nesta modalidade de autocomposição, como é facultado ao conciliador dar sugestões e orientar o possível acordo, o resultado é, via de regra, parcialmente satisfatório para alguma das partes do litígio. Tourinho e Junior $(2007$, p.80) alegam que a conciliação significa "composição amigável sem que se verifique alguma concessão por quaisquer das partes a respeito do pretenso direito alegado ou extinção da obrigação civil ou comercial (renúncia ao direito, reconhecimento do pedido, desistência da ação)".

Nessa toada, é possível deduzir que a conciliação, comparada à mediação, é mais rápida e menos desgastante, pois não é preciso esperar os ânimos se acalmarem, tampouco é preciso estimular as partes conflitantes a irem em busca de um acordo por si mesmas. Ao comparar a mediação e a conciliação, Angelica Arruda Alvim (et al, 2016, p.255), a respeito das diferenças de atuação do mediador e conciliador, descreve que:

Essas diferenças demonstram que a atuação do mediador é mais profunda, já que deverá lidar com aspectos emocionais ou, até, sentimentais das partes, com o intuito de restaurar a relação antes existente entre elas. Sob esse prisma, a solução obtida pela mediação tende a ser mais estável que aquela decorrente da conciliação, já que o conciliador ocupa-se de dar fim ao litígio, sem se ocupar, necessariamente, com aspectos (psicológicos, por exemplo) que não se encontram manifestos. A conciliação, assim, pode ser solução mais satisfatória para eventos instantâneos, mas a mediação é a via mais adequada para problemas que emergem de relações duradouras [...]

Didier, resumidamente, aponta esclarecimentos sobre os métodos de solução de conflitos e faz um paralelo à arbitragem (2015, p.275):

Mediação e conciliação são formas de solução de conflito pelas quais um terceiro intervém em um processo negociai, com a função de auxiliar as partes a chegar à autocomposição. Ao terceiro não cabe resolver o problema, como acontece na arbitragem: o mediador/conciliador exerce um papel de catalisador da solução negocial do conflito.

Assim, retomando esse conceito, cuja compreensão faz-se imprescindível para a presente discussão, a arbitragem, segundo Rodovalho $(2015$, p.10) é um "Método de solução extrajudicial de conflitos. Podemos, então, conceituar a arbitragem como sendo o processo através do qual a 
controvérsia existente entre as partes é decidida por terceiro ou terceiros (árbitros) imparciais, e não pelo Poder Judiciário (juízes)".

Diante do exposto, a evolução científica processual destaca a necessidade de um novo paradigma para os métodos alternativos de resolução de conflitos. Há muito estudado durante as duas últimas décadas, porém, sem o merecido destaque e sem aprimoradas políticas públicas para a implantação e implementação desse novo modelo judicial como meio de cultura social.

\section{CONCLUSÃO}

Conforme se verifica, a intenção de incluir a mediação e conciliação como métodos alternativos de solução de conflito justifica-se ante a necessidade de apresentar métodos diferentes de um processo para a resolução de conflitos, com objetivo de diminuir as demandas nos fóruns e tribunais brasileiros, geradas pela instauração exaustiva de processos no judiciário; ante a necessidade de atender os princípios processuais existentes, como o da celeridade e o da economia processuais; e ante a falta de estrutura do judiciário para resolver todas as demandas.

Desta forma, conclui-se, que as audiências de conciliação e mediação trazem não somente a técnica de ajudar os tribunais, evitando interposição de processos que podem ser resolvidos antes. Também servem como formas de composição amigável entre as partes, haja vista que seu estímulo é consensual, contribuindo para que os litigantes resolvam entre si aquilo que os fazem conflitar- gerando, assim, bons resultados à medida que atinge seu objetivo ao compor as partes e evitar a distribuição de um novo processo.

\section{REFERÊNCIAS BIBLIOGRÁFICAS}

BRASIL. Constituição (1988). Constituição da República Federativa do Brasil. Brasília, DF, Senado, 1998.

BRASIL. Código de Processo Civil. Lei no 13.105, de 16 de março de 2015. Disponível em: < http://www.planalto.gov.br/ccivil_03/_ato2015-2018/2015/lei/l13105.htm>. Acesso em: 31 mar. 2017.

CAPPELETTI, Mauro. Os métodos alternativos de solução de conflitos no quadro do movimento universal de acesso à justiça. São Paulo: Revista Forense, 1994.

CAPPELLETTI, Mauro; GARTH, Bryant. Acesso à justiça. Trad. Ellen Gracie Northfleet. Porto Alegre: Revista Antonio Fabris, 2002.

FRANCO, Selton. Introdução ao estudo de direito. 2014. Disponível em: <https://www.passeidireto.com/disciplina/introducao-ao-estudo-de-direito>. Acesso: 01 abr. 2017.

JUNIOR, Fredie Didier. Curso de direito processual civil: introdução ao direito processual civil, parte geral e processo de conhecimento I. 17. ed. Salvador: Ed. Jus Podivm, 2015.

OLIVEIRA, Adriana Maria Evaristo Martinez de. et al. Normas e padrões para trabalhos acadêmicos e científicos da unoeste. 3 ed. Presidente Prudente: Universidade do Oeste Paulista, 2015. Disponível em: <http://www.unoeste.br/site/biblioteca/documentos/ManualNormalizacao.pdf?v=6>. Acesso em: 31 mar. 2017.

ORDEM DOS ADVOGADOS DO BRASIL. Novo código de processo civil anotado. Porto Alegre: OAB RS, 2016. 
THEODORO JÚNIOR, Humberto. Curso direito processual civil: geral do direito processual civil e processo de conhecimento - vol 1. 57. ed. São Paulo: Saraiva, 2016.

WAMBIER, Teresa Arruda Alvim; et al. Primeiros comentários ao novo código de processo civil: artigo por artigo. 1. ed. - São Paulo: Editora Revista dos Tribunais, 2015. 